\title{
A Computational Model for Biomechanical Effects of Arterial Compliance Mismatch
}

\author{
Fan He, ${ }^{1}$ Lu Hua, ${ }^{2}$ and Li-jian Gao ${ }^{2}$ \\ ${ }^{1}$ Department of Mechanics, School of Science, Beijing University of Civil Engineering and Architecture, Beijing 100044, China \\ ${ }^{2}$ Key Laboratory of Clinical Trial Research in Cardiovascular Drugs, Ministry of Health, Fuwai Hospital, \\ National Center for Cardiovascular Diseases, Chinese Academy of Medical Sciences, and Peking Union Medical College, \\ Beijing 100037, China \\ Correspondence should be addressed to Fan He; hefan@bucea.edu.cn
}

Received 6 October 2014; Revised 17 January 2015; Accepted 26 February 2015

Academic Editor: Andrea Cereatti

Copyright (C) 2015 Fan He et al. This is an open access article distributed under the Creative Commons Attribution License, which permits unrestricted use, distribution, and reproduction in any medium, provided the original work is properly cited.

Background. Compliance mismatch is a negative factor and it needs to be considered in arterial bypass grafting. Objective. A computational model was employed to investigate the effects of arterial compliance mismatch on blood flow, wall stress, and deformation. Methods. The unsteady blood flow was assumed to be laminar, Newtonian, viscous, and incompressible. The vessel wall was assumed to be linear elastic, isotropic, and incompressible. The fluid-wall interaction scheme was constructed using the finite element method. Results. The results show that there are identical wall shear stress waveforms, wall stress, and strain waveforms at different locations. The comparison of the results demonstrates that wall shear stresses and wall strains are higher while wall stresses are lower at the more compliant section. The differences promote the probability of intimal thickening at some locations. Conclusions. The model is effective and gives satisfactory results. It could be extended to all kinds of arteries with complicated geometrical and material factors.

\section{Introduction}

Arteriosclerosis is a frequent cardiovascular disease and has become one of the most leading causes of death in the modern society. Arteriosclerosis causes the deposition of low-density lipoprotein, atheroma, and cholesterol [1-3] and results in stenosis. It has been proven that the initiation and development of arteriosclerosis are related to hemodynamics and vessel wall mechanics [4-7]. Stenosis increases flow resistance in arteries and causes abnormal flow distributions, which may be related to thrombus formation and plaque rupture. Thus, stroke and heart attack are directly led [8]. It is well known that stenosis provokes abnormal flow and the resulting flow disorder further worsens the disease [9-14]. It is established that the arterial bypass grafting is effective in repairing the diseased arteries. Usually, the surgery is successful at the early stage of the operation; however there is a technical challenge for the surgeon due to the unacceptably high rate of postoperative occlusion [15]. Though the grafting has been performed extensively, the artificial or other selfbody blood vessels are used in the grafting and thus a usual and troublesome problem is caused; that is, there is compliance mismatch in arterial bypass grafting. Compliance mismatch caused by different wall stiffness has been shown to reduce graft patency [16].

In this paper, a model composed of three arterial segments with different wall stiffness was constructed. Furthermore, a fluid-wall interaction was introduced to investigate blood flow and mechanical characteristics. In the model, the same walls at two ends were stiffer than the wall in the middle. This model was employed to simulate arterial compliance mismatch. The aim of this paper is to study the effects of arterial compliance mismatch on flow distributions, wall stresses, and deformations and find out the stiffnessinduced differences of mechanical properties in the model. This study is helpful in making a detailed understanding of 
biomechanical effects of compliance mismatch. The understanding may be important in the selection of arterial grafts and in designing artificial blood vessels.

\section{The Model}

2.1. Geometry. Figure 1 shows the geometry of the model. The parameters of a human carotid artery were selected for the calculation [17]. The outer diameter was $D_{1}=10 \mathrm{~mm}$ and the inner diameter was $D_{0}=8 \mathrm{~mm}$ (a straight round vessel). The length of each wall was $50 \mathrm{~mm}$. To minimize the influence of input velocity specification on the flow dynamics in the segments of interest, the segment in the upstream direction was extended [18]. An extension of $30 \mathrm{~mm}$ at the inflow side was added to the model where the inlet boundary condition was specified; thus, the total length was $180 \mathrm{~mm}$. In this model, three arterial segments had the same diameter because we only wanted to investigate the effects of compliance mismatch. The effects of different geometrical structures were not considered here. The junction between two segments is related to geometrical structures and suture lines and angles. Therefore the mechanical properties of the junction were not considered in the paper and may be included in our future work.

2.2. Fluid and Wall Formulation. For the fluid model, the Navier-Stokes equations were used as the governing equations. Blood was modeled as an incompressible and Newtonian fluid, with a density of $1050 \mathrm{~kg} / \mathrm{m}^{3}$ and a dynamic viscosity of $0.0035 \mathrm{~Pa} \cdot \mathrm{s}$.

For the wall model, the linear elastic constitutive equations were used as the governing equations. The material constants used in the linear elastic relationship were Young's modulus and Poisson's ratio. Here, we made a compliance difference according to different values of Young's modulus. Young's modulus of the middle artery was $5 \mathrm{MPa}$ and the moduli of the arteries at two ends were $200 \mathrm{MPa}$ [19]. Poisson's ratio was 0.499 .

Time-dependent flow condition measured by Gijsen et al. [20] (Figure 2) was applied at the inlet. The period of the flow waveform was $T=1 \mathrm{~s}$. Then, the Reynolds number for the Newtonian fluid flow, defined as $\operatorname{Re}=\rho D_{0} V / \mu$, varied from about 190 (diastole) to 500 (peak systole), while based on the period of the flow pulse, the Womersley number, defined as $\alpha=\left(D_{0} / 2\right) \sqrt{2 \pi \rho / T \mu}$, was equal to 5.5 . At the outlet, a zero normal traction was applied. On the walls, we specify no-slip boundary conditions for the flow. The initial conditions in the whole field were assumed to be zero $[21,22]$. In the structural mechanics part, as a boundary condition, we set that one end of the blood vessel was entirely fixed and the other end was free.

This fluid-structure interaction technique allows studying the arterial fluid mechanics by accounting for both the instantaneous fluid forces acting on the wall and the effects of the wall motion on the fluid dynamic field. Fluid forces, wall displacements, and velocities are transferred across the fluid-structure interface.

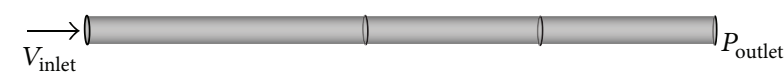

FIGURE 1: The geometry of the model.

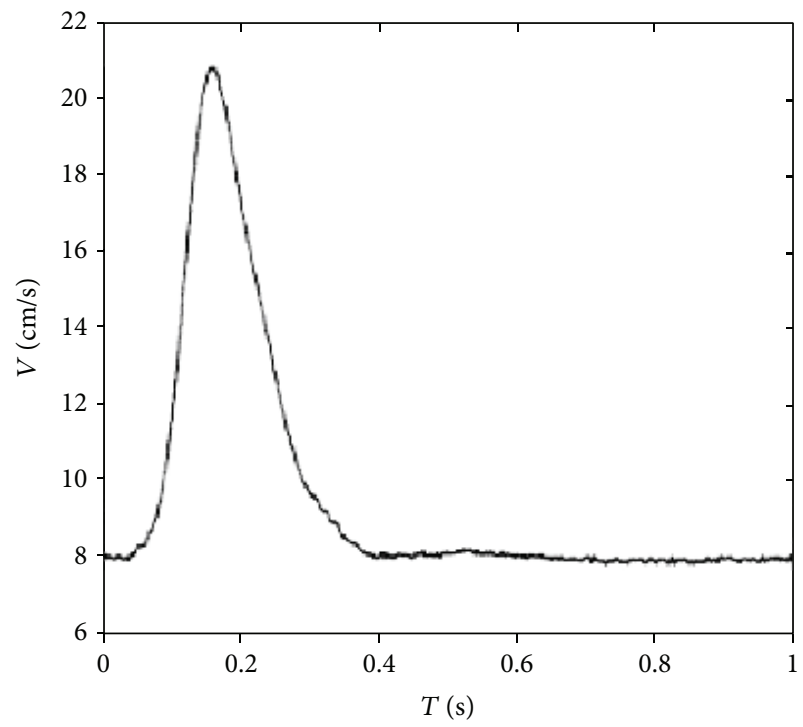

FIgURE 2: The map of velocity at the inlet.

2.3. Numerical Methods. The fluid-wall interaction scheme was constructed using the finite element method [23]. The Arbitrary Lagrangian-Eulerian (ALE) formulation was used. It was an implicit procedure in time. A Crank-Nicolson time stepping scheme was employed. The fluid domain was discretized by unstructured tetrahedral four-node elements of 49461. The wall domain was discretized by hexahedral eight-node elements of 12960. Mesh convergence studies in which flow parameters and stress/displacement analyses with finer meshes were tested established that the results are independent of mesh density. Further increase of the mesh size did not significantly change the final results. We performed a maximum of 100 iterations within each time step of $0.01 \mathrm{~s}$. Three cycles were required to achieve convergent and stable solutions for the transient analysis [24, 25]. The time step independency studies were performed $(0.005 \mathrm{~s}$ and $0.008 \mathrm{~s}$ ). The resulting values of the velocity from these time steps agreed to within 5\%. The relative tolerance for all degrees of freedom was set to 0.0001 .

\section{Results and Discussion}

3.1. Blood Flow Characteristics. Figure 3 presents the calculated velocity contours at three time points, that is, diastole end, systole peak, and diastole begin. In Figure $3, L$ represents the distance away from the inlet. Thus, $L=70 \mathrm{~mm}, 100 \mathrm{~mm}$, and $140 \mathrm{~mm}$ denote the locations of the beginning, middle, and ending tubes in Figure 1, respectively. The entrance effects are considered when selecting the locations; therefore it is ensured that $L=70 \mathrm{~mm}$ is excluded in the entrance zone. 


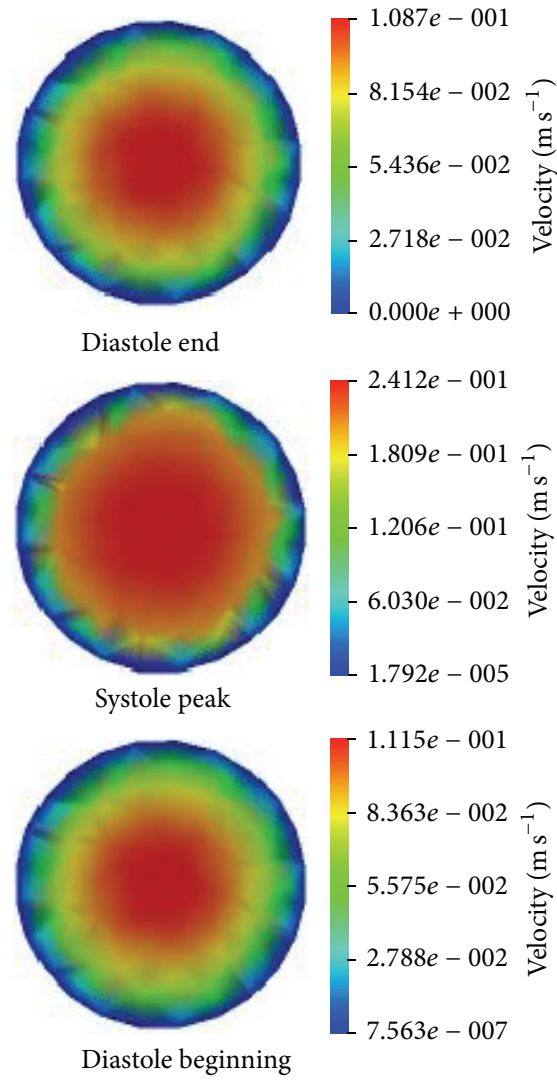

(a)

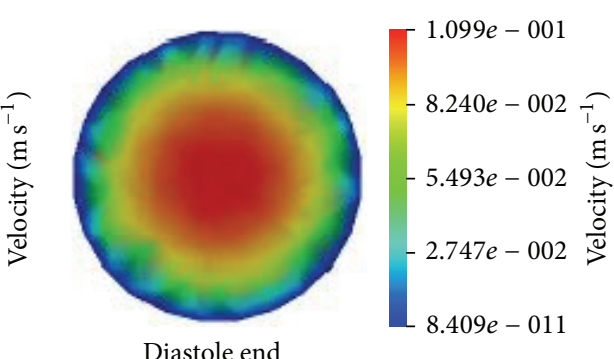

Diastole end
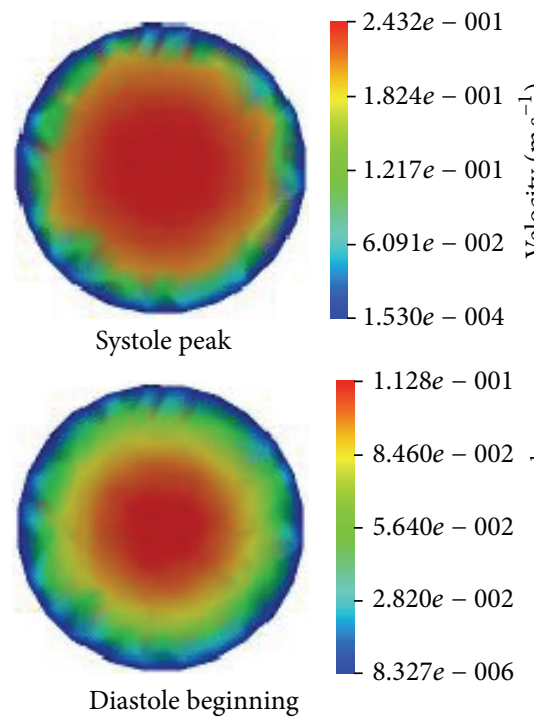

(b)

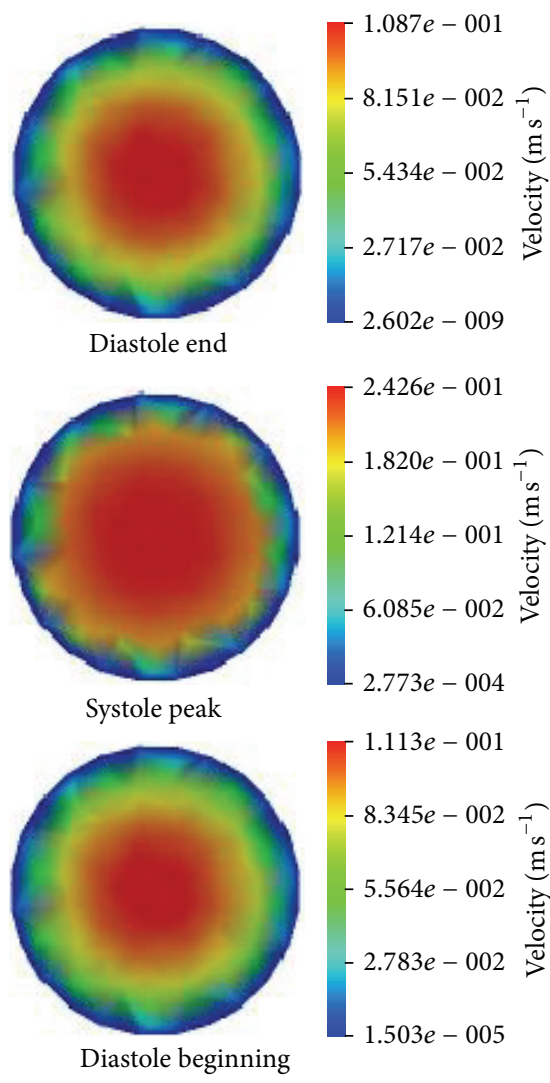

(c)

Figure 3: The velocity contours at different time. (a) $L=70 \mathrm{~mm}$, (b) $L=100 \mathrm{~mm}$, and (c) $L=140 \mathrm{~mm}$.

It can be seen that the velocity distributions at different locations are almost identical at the same time. The maximum velocity values at $L=100 \mathrm{~mm}$ are higher than those at other locations. The velocity profiles in Figure 3 are not axisymmetric. The reason is that the deformation of the tube is accompanied with buckling. The buckling breaks the symmetry. The reason of the buckling could be found in Han's work [26].

Here, the maximum wall shear stresses at three locations are presented (Figure 4). The distributions of wall shear stresses closely resemble the inlet velocity waveform. However obviously, the wall shear stresses at $L=100 \mathrm{~mm}$ are highest in Figure 4. The characteristics of time-dependent pressures of the three locations are very much similar as shown in Figure 5. According to the results, there is the evidence that a variation of Young's modulus (arterial compliance) does not change the flow distributions. These are in agreement with the results obtained by Valencia and Solis [19].

As we know, the increasing residence time of atherogenic particles, such as platelets, leukocytes, and macrophages, could increase the probability of deposition or adhesion of blood particles with the arterial wall. The residence time is correlated with wall shear stress. Low wall shear stress is prone to increase the residence time and it can promote plaques formation and intimal thickening [27]. Accordingly,

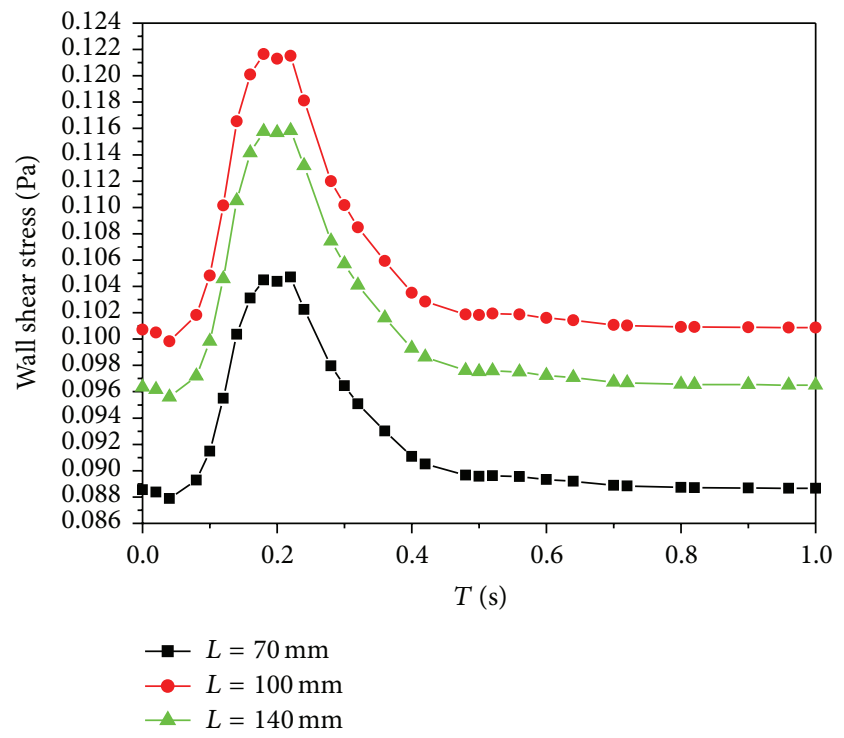

FIgURE 4: The distributions of time-dependent wall shear stresses.

the wall shear stresses at the middle wall are more advantageous than those at the beginning and ending walls; that is, stiffer wall may induce lower wall shear stresses and 


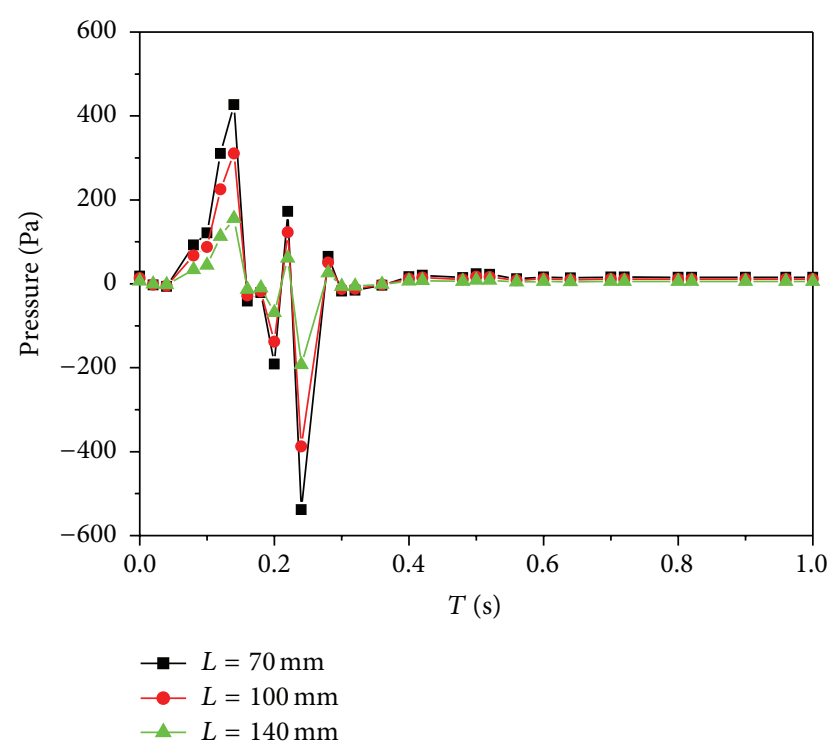

FIGURE 5: The distributions of time-dependent pressures.

TABLE 1: The maximum and minimum circumferential stresses at three locations.

\begin{tabular}{lcc}
\hline$L(\mathrm{~mm})$ & Maximum stress $(\mathrm{Pa})$ & Minimum stress $(\mathrm{Pa})$ \\
\hline 70 & 2088.38 & -2465.67 \\
100 & 760.663 & -886.142 \\
140 & 919.78 & -1078.18 \\
\hline
\end{tabular}

promote arterial diseases more easily. Therefore the arterial compliance mismatch may bring disadvantageous effects on wall shear stresses and result in the occurrence of the particle deposition at stiffer arterial segments.

3.2. Wall Mechanics. The stresses and strains in an arterial wall are caused by both blood pressure and wall shear. It is known that circumferential stresses and strains are directly related to the remodeling of arterial walls and affect the structure and physiological function of arterial walls. Therefore, the circumferential stresses and strains of the inner walls at three locations are concerned in this study. The time dependence of the circumferential stresses is the same as that of the pressures (Figure 6). Meanwhile, the relationship between the stress and strain is linear elastic. Thus, the distributions of the circumferential strains are similar to those of the circumferential stresses (Figure 7).

The absolute maximum and minimum values of the circumferential stresses at $L=100 \mathrm{~mm}$ are lowest as shown in Table 1. It is known that a high stress level tends to induce a concentrated stress. The structures of cells and tissues enduring long-term high stresses would be changed. Therefore a high stress level is harmful. From the point, low circumferential stresses adapt to keep arterial tissues growing normally and healthily.

The absolute maximum and minimum values of the circumferential strains at $L=100 \mathrm{~mm}$ are highest as shown in Table 2. Moreover, the strains at $L=100 \mathrm{~mm}$ are much higher

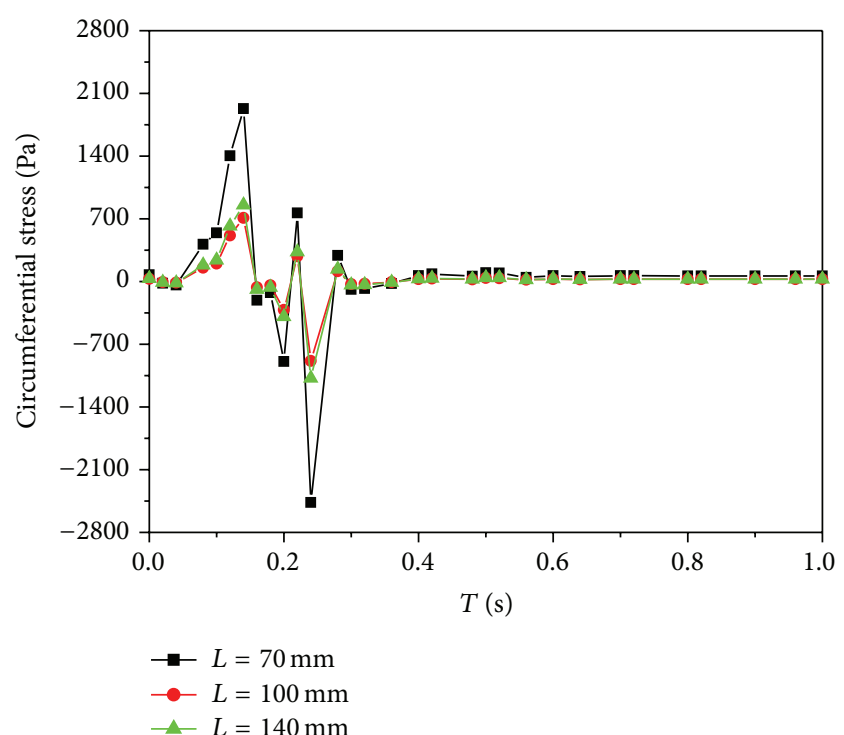

FIgURE 6: The distributions of time-dependent circumferential stresses.

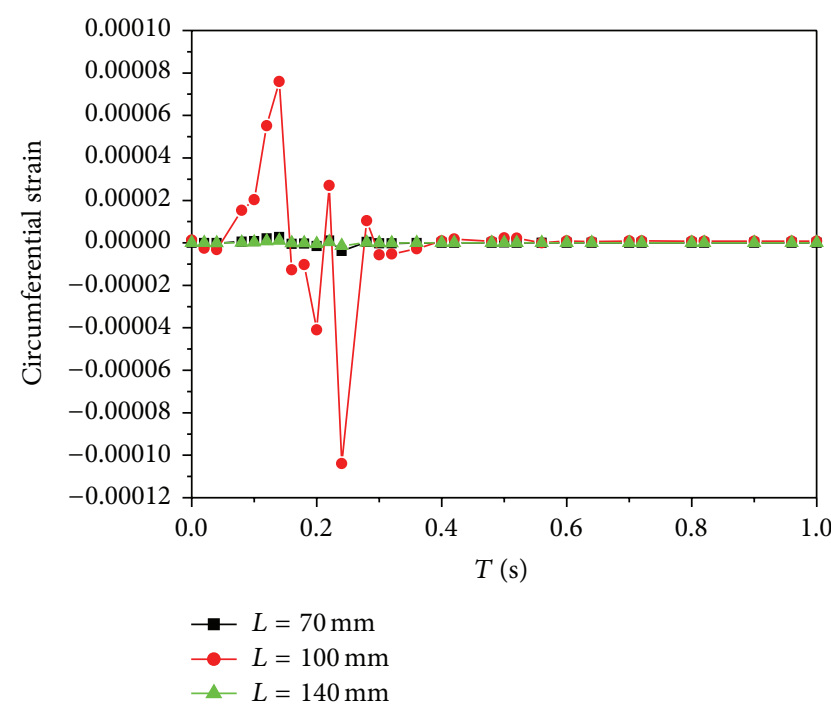

FIgURE 7: The distributions of time-dependent circumferential strains.

TABLE 2: The maximum and minimum circumferential strains at three locations.

\begin{tabular}{lcc}
\hline$L(\mathrm{~mm})$ & Maximum strain & Minimum strain \\
\hline 70 & $3.10779 e-6$ & $-3.83545 e-6$ \\
100 & $8.49064 e-5$ & $-1.04459 e-4$ \\
140 & $1.13953 e-6$ & $-1.39365 e-6$ \\
\hline
\end{tabular}

compared to other locations, so that the strain distributions at $L=70 \mathrm{~mm}$ and $140 \mathrm{~mm}$ are unclear in Figure 7 .

Cyclic strain may play a role in atherosclerosis. It is possible that there exists a correlation between high cyclic strain levels and enhanced macromolecular permeability, in turn leading to atherosclerotic inflammation [28]. Straining 
with a large strain magnitude results in a negative effect on the mechanical properties of the tissue [29]. Though the strain magnitude is very small in Table 2, the strain distributions are nonuniform. The strain magnitude at $L=100 \mathrm{~mm}$ is higher than that at other locations. If the outlet pressure is enhanced, the strain magnitude is also increased as a result. In that way, the strain magnitude at $L=100 \mathrm{~mm}$ could affect the mechanical properties of the tissue unfavorably when it attains to a degree. The strains at other locations are more advantageous. From this aspect, the strains in the middle artery are not preponderant in the tissue growth.

3.3. Limitations of the Model. Several simplifying assumptions were made in the current analysis, which ignored anisotropy, non-linear elastic properties of the arterial wall, non-Newtonian blood, and so forth. All these higher order effects can be considered in future studies.

\section{Conclusions}

A computational model for biomechanical effects of arterial compliance mismatch on blood flow and mechanical characteristics has been constructed. The flow distributions and wall stresses and deformations based on the model have been performed numerically. The results indicate that the arterial compliance mismatch could induce the differences of mechanical characteristics between different locations. The differences promote the probability of intimal thickening at some locations. Compliance mismatch is a negative factor and it needs to be considered cautiously in arterial bypass grafting. Consequently, the avoidance of compliance mismatch could enhance graft patency. The constructed model in this paper gives satisfactory results and may be better in expressing biomechanical properties of arterial compliance mismatch. The computational model is effective and could be extended to all kinds of arteries with complicated geometrical and material factors.

\section{Conflict of Interests}

The authors declare that there is no conflict of interests regarding the publication of this paper.

\section{Acknowledgments}

The authors thank National Natural Science Foundation of China (81401492) and the Science and Technology Project of Beijing Municipal Commission of Education (KM201510016012) for financially supporting this research. The work is also supported by the Foundation of Research and Innovation Team (PXM 2013_014210_000173) and the Academic Innovation Team of Beijing University of Civil Engineering and Architecture (21221214111).

\section{References}

[1] P. F. Davies, T. Mundel, and K. A. Barbee, "A mechanism for heterogeneous endothelial responses to flow in vivo and in vitro," Journal of Biomechanics, vol. 28, no. 12, pp. 1553-1560, 1995.

[2] R. N. Pralhad and D. H. Schultz, "Modeling of arterial stenosis and its applications to blood diseases," Mathematical Biosciences, vol. 190, no. 2, pp. 203-220, 2004.

[3] I. Marshall, S. Zhao, P. Papathanasopoulou, P. Hoskins, and X. Y. Xu, "MRI and CFD studies of pulsatile flow in healthy and stenosed carotid bifurcation models," Journal of Biomechanics, vol. 37, no. 5, pp. 679-687, 2004.

[4] D. N. Ku, D. P. Giddens, C. K. Zarins, and S. Glagov, "Pulsatile flow and atherosclerosis in the human carotid bifurcation: positive correlation between plaque location and low and oscillating shear stress," Arteriosclerosis, vol. 5, no. 3, pp. 293302, 1985.

[5] R. M. Nerem, "Vascular fluid mechanics, the arterial wall, and atherosclerosis," Journal of Biomechanical Engineering, vol. 114, no. 3, pp. 274-282, 1992.

[6] D. P. Giddens, C. K. Zarins, and S. Glagov, "The role of fluid mechanics in the localization and detection of atherosclerosis," Journal of Biomechanical Engineering, vol. 115, no. 4, pp. 588594, 1993.

[7] R. Ross, "The pathogenesis of atherosclerosis: a perspective for the 1990s," Nature, vol. 362, no. 6423, pp. 801-809, 1993.

[8] D. Tang, C. Yang, and D. N. Ku, "3-D thin-wall model with fluid-structure interactions for blood flow in carotid arteries with symmetric and asymmetric stenoses," Computers and Structures, vol. 72, no. 1, pp. 357-377, 1999.

[9] M. Bathe and R. D. Kamm, "A fluid-structure interaction finite element analysis of pulsatile blood flow through a compliant stenotic artery," Journal of Biomechanical Engineering, vol. 121, no. 4, pp. 361-369, 1999.

[10] D. Tang, C. Yang, S. Kobayashi, and D. N. Ku, "Generalized finite difference method for 3-D viscous flow in stenotic tubes with large wall deformation and collapse," Applied Numerical Mathematics, vol. 38, no. 1-2, pp. 49-68, 2001.

[11] D. Tang, C. Yang, H. Walker, S. Kobayashi, and D. N. Ku, "Simulating cyclic artery compression using a 3D unsteady model with fluid-structure interactions," Computers and Structures, vol. 80, no. 20-21, pp. 1651-1665, 2002.

[12] M. S. Moayeri and G. R. Zendehbudi, "Effects of elastic property of the wall on flow characteristics through arterial stenoses," Journal of Biomechanics, vol. 36, no. 4, pp. 525-535, 2003.

[13] A. Valencia and M. Villanueva, "Unsteady flow and mass transfer in models of stenotic arteries considering fluid-structure interaction," International Communications in Heat and Mass Transfer, vol. 33, no. 8, pp. 966-975, 2006.

[14] M. X. Li, J. J. Beech-Brandt, L. R. John, P. R. Hoskins, and W. J. Easson, "Numerical analysis of pulsatile blood flow and vessel wall mechanics in different degrees of stenoses," Journal of Biomechanics, vol. 40, no. 16, pp. 3715-3724, 2007.

[15] F. Loth, S. A. Jones, C. K. Zarins et al., "Relative contribution of wall shear stress and injury in experimental intimal thickening at PTFE end-to-side arterial anastomoses," Journal of Biomechanical Engineering, vol. 124, no. 1, pp. 44-51, 2002.

[16] G. S. Kassab and J. A. Navia, "Biomechanical considerations in the design of graft: the homeostasis hypothesis," Annual Review of Biomedical Engineering, vol. 8, pp. 499-535, 2006.

[17] T. J. Pedley, The Fluid Mechanics of Large Blood Vessels, Cambridge University Press, Cambridge, UK, 1980. 
[18] J. P. Abraham, E. M. Sparrow, and R. D. Lovik, "Unsteady, threedimensional fluid mechanic analysis of blood flow in plaquenarrowed and plaque-freed arteries," International Journal of Heat and Mass Transfer, vol. 51, no. 23-24, pp. 5633-5641, 2008.

[19] A. Valencia and F. Solis, "Blood flow dynamics and arterial wall interaction in a saccular aneurysm model of the basilar artery," Computers and Structures, vol. 84, no. 21, pp. 1326-1337, 2006.

[20] F. J. H. Gijsen, E. Allanic, F. N. van de Vosse, and J. D. Janssen, "The influence of the non-Newtonian properties of blood on the flow in large arteries: unsteady flow in a 90。 curved tube," Journal of Biomechanics, vol. 32, no. 7, pp. 705-713, 1999.

[21] E. S. Weydahl and J. E. Moore Jr., "Dynamic curvature strongly affects wall shear rates in a coronary artery bifurcation model," Journal of Biomechanics, vol. 34, no. 9, pp. 1189-1196, 2001.

[22] Y. L. Lu, X. Y. Lu, L. X. Zhuang, and W. Wang, "Breaking symmetry in non-planar bifurcations: distribution of flow and wall shear stress," Biorheology, vol. 39, no. 3-4, pp. 431-436, 2002.

[23] F. He, "Wave propagation in an elastic tube: a numerical study," International Journal of Computational Fluid Dynamics, vol. 27, no. 3, pp. 164-172, 2013.

[24] T. Gebreegziabher, E. M. Sparrow, J. P. Abraham, E. Ayorinde, and T. Singh, "High-frequency pulsatile pipe flows encompassing all flow regimes," Numerical Heat Transfer Part A: Applications, vol. 60, no. 10, pp. 811-826, 2011.

[25] N. M. Naughton, B. D. Plourde, J. R. Stark, S. Hodis, and J. P. Abraham, "Impacts of waveforms on the fluid flow, wall shear stress, and flow distribution in cerebral aneurysms and the development of a universal reduced pressure," Journal of Biomedical Science and Engineering, vol. 7, no. 1, pp. 7-14, 2014.

[26] H.-C. Han, "A biomechanical model of artery buckling," Journal of Biomechanics, vol. 40, no. 16, pp. 3672-3678, 2007.

[27] T. A. Salam, A. B. Lumsden, W. D. Suggs, and D. N. Ku, "Low shear stress promotes intimal hyperplasia thickening," Journal of Vascular Investigation, vol. 2, no. 1, pp. 12-22, 1996.

[28] H. F. Younis, M. R. Kaazempur-Mofrad, R. C. Chan et al., "Hemodynamics and wall mechanics in human carotid bifurcation and its consequences for atherogenesis: investigation of inter-individual variation," Biomechanics and Modeling in Mechanobiology, vol. 3, no. 1, pp. 17-32, 2004.

[29] R. A. Boerboom, M. P. Rubbens, N. J. B. Driessen, C. V. C. Bouten, and F. P. T. Baaijens, "Effect of strain magnitude on the tissue properties of engineered cardiovascular constructs," Annals of Biomedical Engineering, vol. 36, no. 2, pp. 244-253, 2008. 

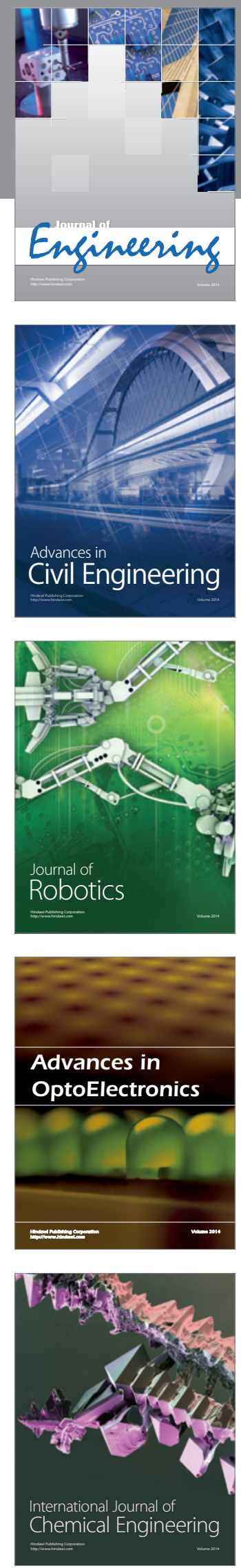

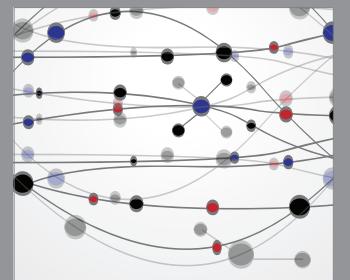

The Scientific World Journal
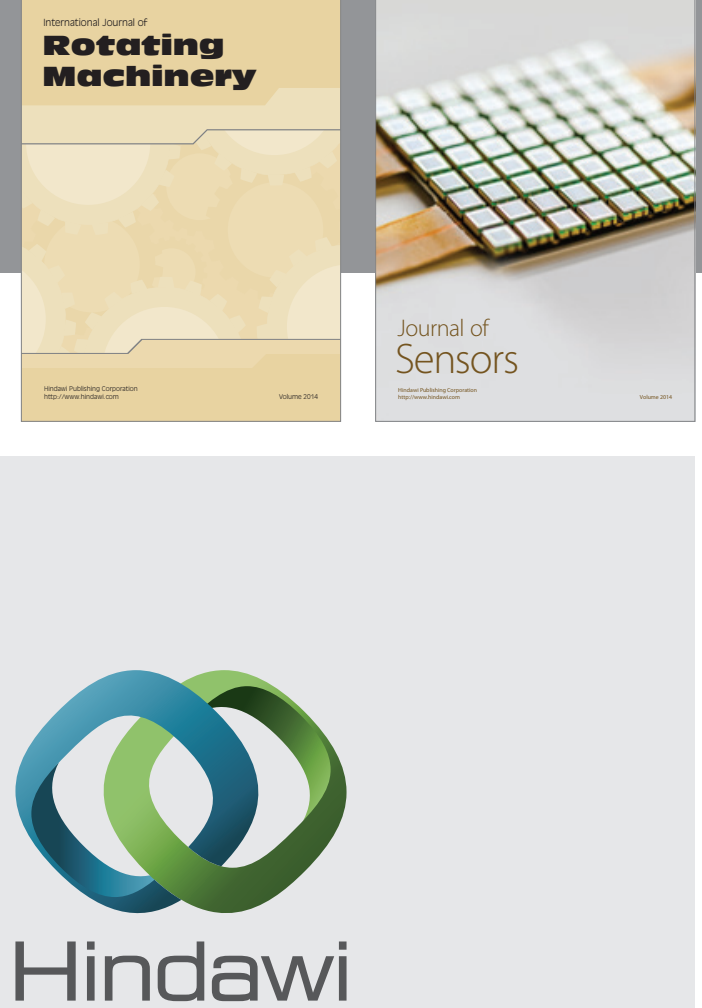

Submit your manuscripts at http://www.hindawi.com
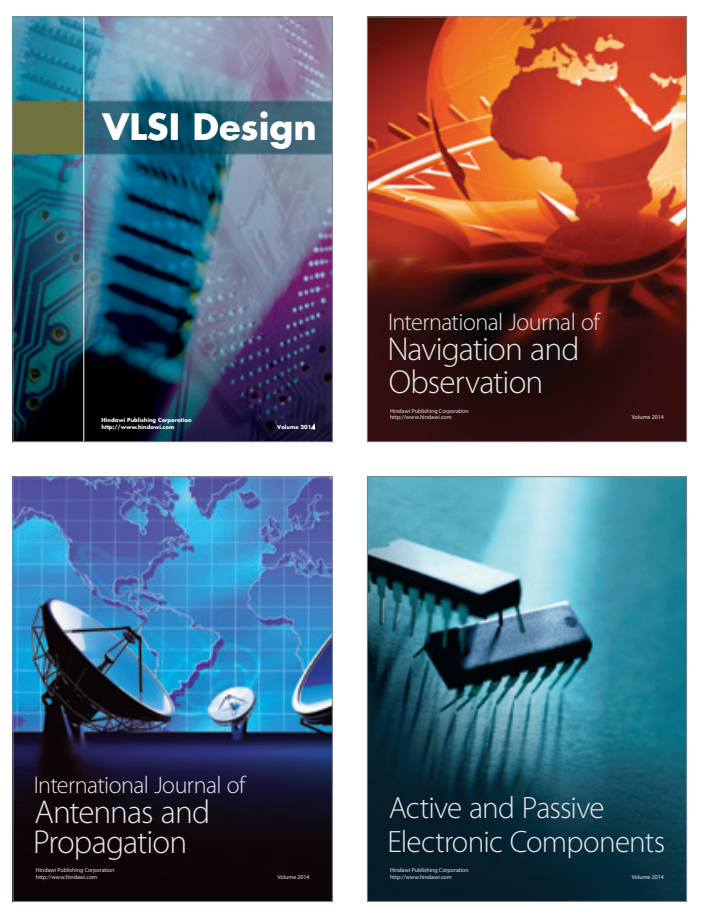
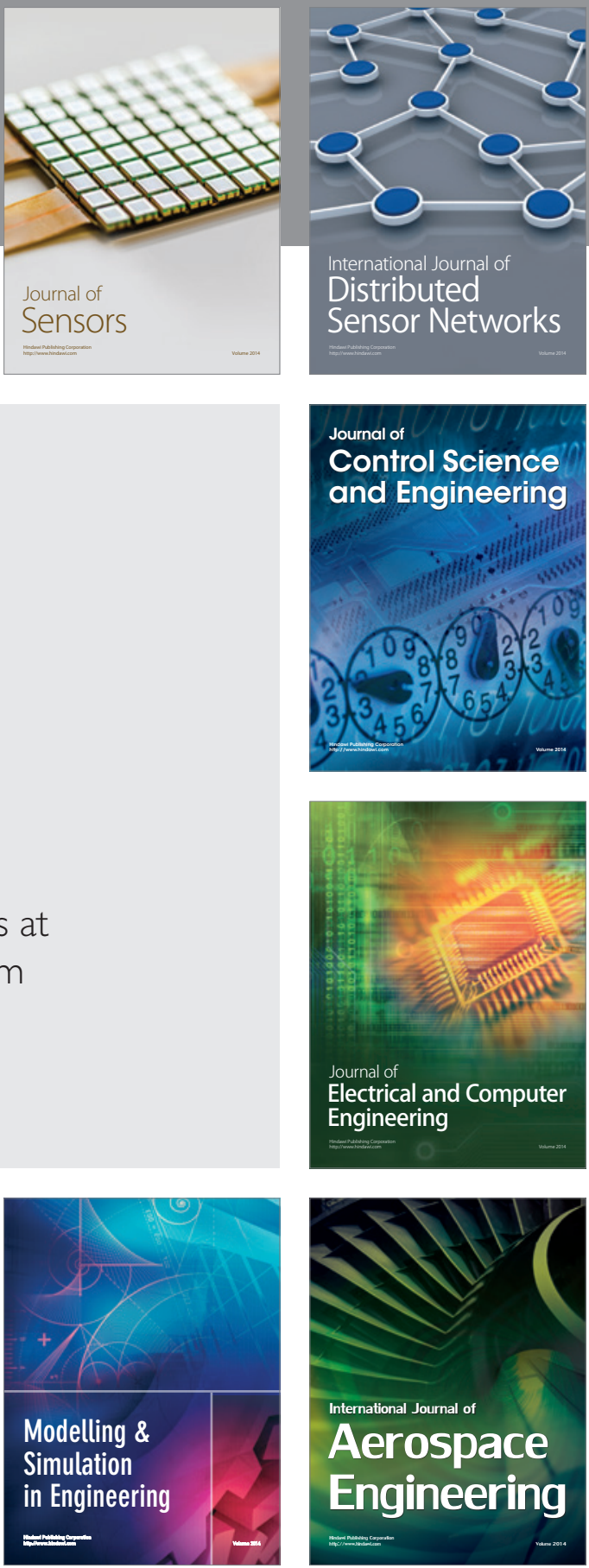

Journal of

Control Science

and Engineering
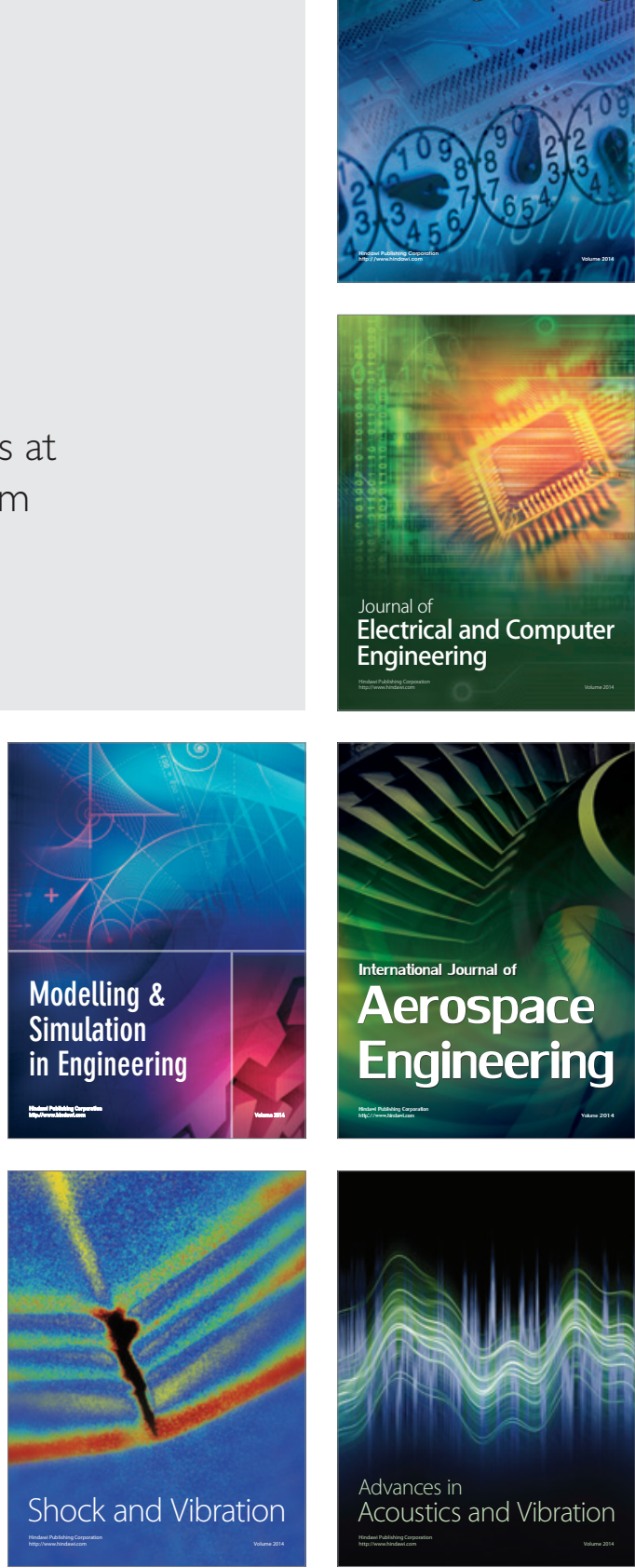